\title{
Controlling Nitrogen Pollution via Encapsulation of Urea Fertilizer in Cross-linked Corn Starch
}

\author{
Khalid A. Ibrahim, ${ }^{\text {abb }}$ Muhammad Y. Naz, ${ }^{c} *$ Shazia Shukrullah, ${ }^{c}$ Shaharin A. Sulaiman, ${ }^{\text {d }}$ \\ Abdul Ghaffar, ${ }^{\mathrm{c}}$ and Nasser M. AbdEl-Salam ${ }^{\mathrm{e}}$
}

\begin{abstract}
High fertilizer inputs augment the reactive nitrogen level in soil, air, and water. Unused reactive nitrogen acts as a pollutant and harms natural resources. This study focused on the thermal processing of corn starch into a coating material using di-sodium tetraborate and urea. The processed corn starch was coated over granular urea in a vertical bed coating reactor. The chemically modified starch, when compared with native starch, exhibited better stability and mechanical strength over time. The modified starch looked like a weak gel, and its loss modulus was dominated by the storage modulus. However, for native starch, the viscous component dominated the elastic component, especially at lower angular frequencies. The nitrogen release from the coated urea was remarkably slower than the uncoated one. A small difference in the peak and final starch viscosities in the presence of urea and borate revealed low thermal cracking of the starch molecules. The surface of the granular urea that was coated with chemically modified corn starch was uniform, dense, hard, and least porous. The uncoated urea granules became released into water in 6 min under gentle shaking, whereas the coated urea took almost 32 min to completely release.
\end{abstract}

Keywords: Corn starch; Rheology; Fluidized bed spray coating; Coated urea; Slow release properties

Contact information: a: College of Engineering, Muzahimiyah Branch, King Saud University, Riyadh 11451, Saudi Arabia; b: Department of Chemical Engineering, Al-Hussein Bin Talal University, Ma'an, Jordan; c: Department of Physics, University of Agriculture, Faisalabad, 38040, Pakistan;

d: Mechanical Engineering Department, Universiti Teknologi Petronas, 32610, Perak, Malaysia;

e: Arriyadh Community College, King Saud University, 11437 Arriyadh, Saudi Arabia;

* Corresponding author: yasin603@yahoo.com

\section{INTRODUCTION}

\section{Conventional Urea Pollution}

Urea is a nitrogen fertilizer, commonly used for the fast and healthy growth of crops. The Haber process is used for commercial scale manufacturing of urea from ammonia and carbon dioxide. Almost 450 million tonnes of nitrogen-containing fertilizers are produced annually through this process. Ammonium nitrate, anhydrous ammonia, and urea are some examples of nitrogen fertilizers. Urea fertilizer contains $46 \%$ nitrogen, which is required for improved plant growth (Galloway and Cowling 2002; Glibert et al. 2006; Naz and Sulaiman 2016a). The fast-growing population of the world needs increased access to food, regardless of economic status. This is a major motive for increased use in the global urea market over the past few decades. Even during the great recession of 2008 to 2009 , market growth was observed in this area. Presently, urea is the most popular and accessible fertilizer for agriculture and other end-uses including livestock feed, ureaformaldehyde resins, and melamine. In 2013, the non-fertilizer segments consumed approximately $15 \%$ of the total urea demand (Xiaofei et al. 2004; Glibert et al. 2006). 
Figure 1 provides an overview of the demand for urea from the past, the present, and the near future.
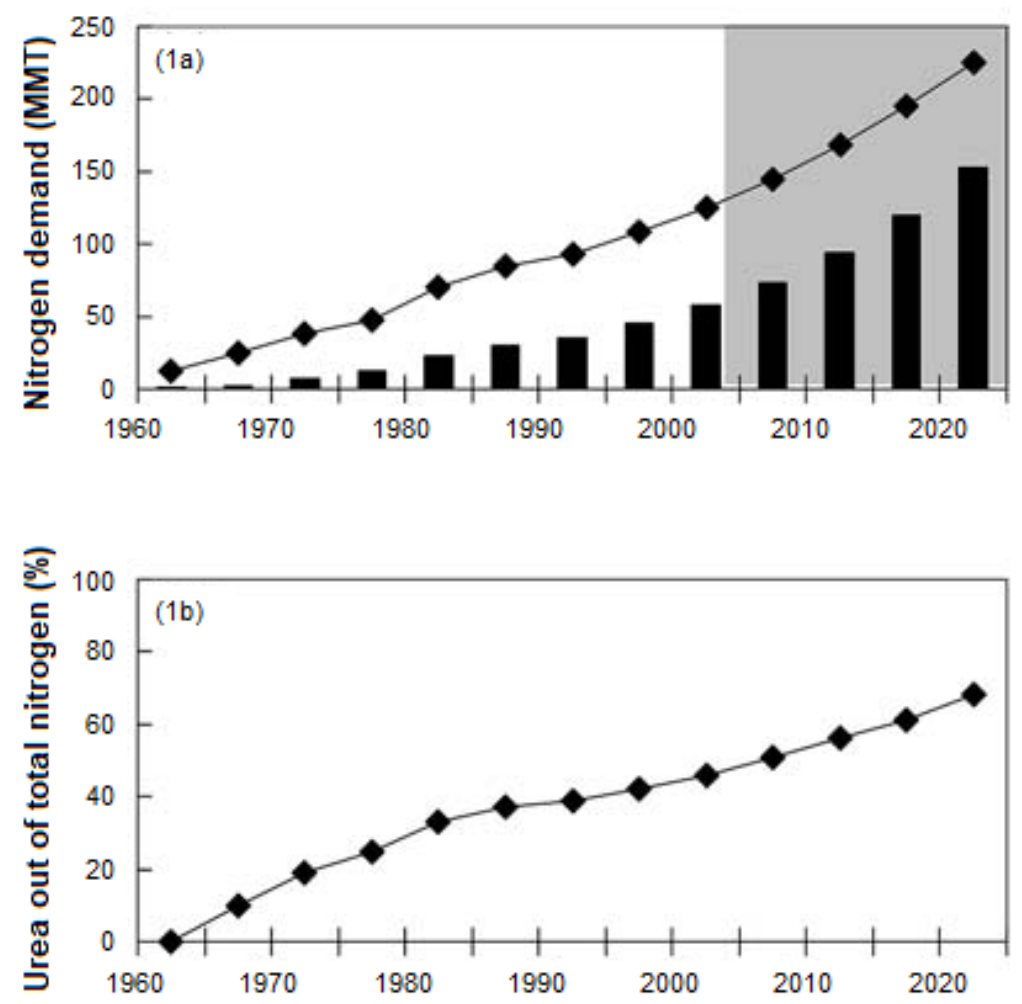

Fig. 1. (a) The line shows the change in world consumption of synthetic nitrogen fertilizers and the bars give the urea consumption since 1960; (b) reports the same data as in (1a) but with urea as a percentage of the total demand of nitrogen

Due to the large input of mineral fertilizers, the global production of crops and livestock has considerably increased over the past century. In response, the loss of reactive nitrogen to the soil, air, and water has augmented as well. Primarily, industrial nitrogen fixation directly contributes to the availability of nitrogen in terrestrial ecosystems. This increase in atmospheric nitrogen concentration also causes a high deposition of nitrogen in agriculture-dominated landscapes (Galloway et al. 2008). The major sources of reactive nitrogen include fertilizers, nitrogen in foods, and airborne nitrogen emissions. Food products account for a major portion of reactive nitrogen (38 to 75\%) in the world. The airborne nitrogen emissions contribute approximately 11 to $36 \%$, while nitrogen fertilizers contribute approximately 11 to $32 \%$ to the reactive nitrogen (Boyer et al. 2002). The surplus or unassimilated reactive nitrogen results in environmental pollution and consequently poor air quality, acidification of lakes and rivers, interruption of the forest development, and degradation of coastal water quality, as explained in Fig. 2. Nitrogen is exported to the aquatic ecosystem due to hydrolysis of urea in the presence of extra-cellular enzymes and microbial consortia. The urea hydrolyzes into $\mathrm{NH}_{4}^{+}$, which changes into $\mathrm{NH}_{3}$, $\mathrm{NO}_{2}^{-} / \mathrm{NO}_{3}^{-}, \mathrm{N}_{2} \mathrm{O}$, and $\mathrm{N}_{2}$. The $\mathrm{NH}_{3}$ is produced during volatilization of urea, $\mathrm{NO}_{2}^{-} / \mathrm{NO}_{3}^{-}$is produced during nitrification whereas $\mathrm{N}_{2} \mathrm{O}$ and $\mathrm{N}_{2}$ are produced during denitrification. Reactive nitrogen can have a more severe impact on phosphorus and carbonate-rich waters. The reactive nitrogen supports the formation of toxic colonial cyanobacteria in the 
phosphorous-rich water. Since bacteria control the nitrogen cycle, the nitrogen cycling rate can be predicted from the moisture, $\mathrm{pH}$, and temperature of the soil.

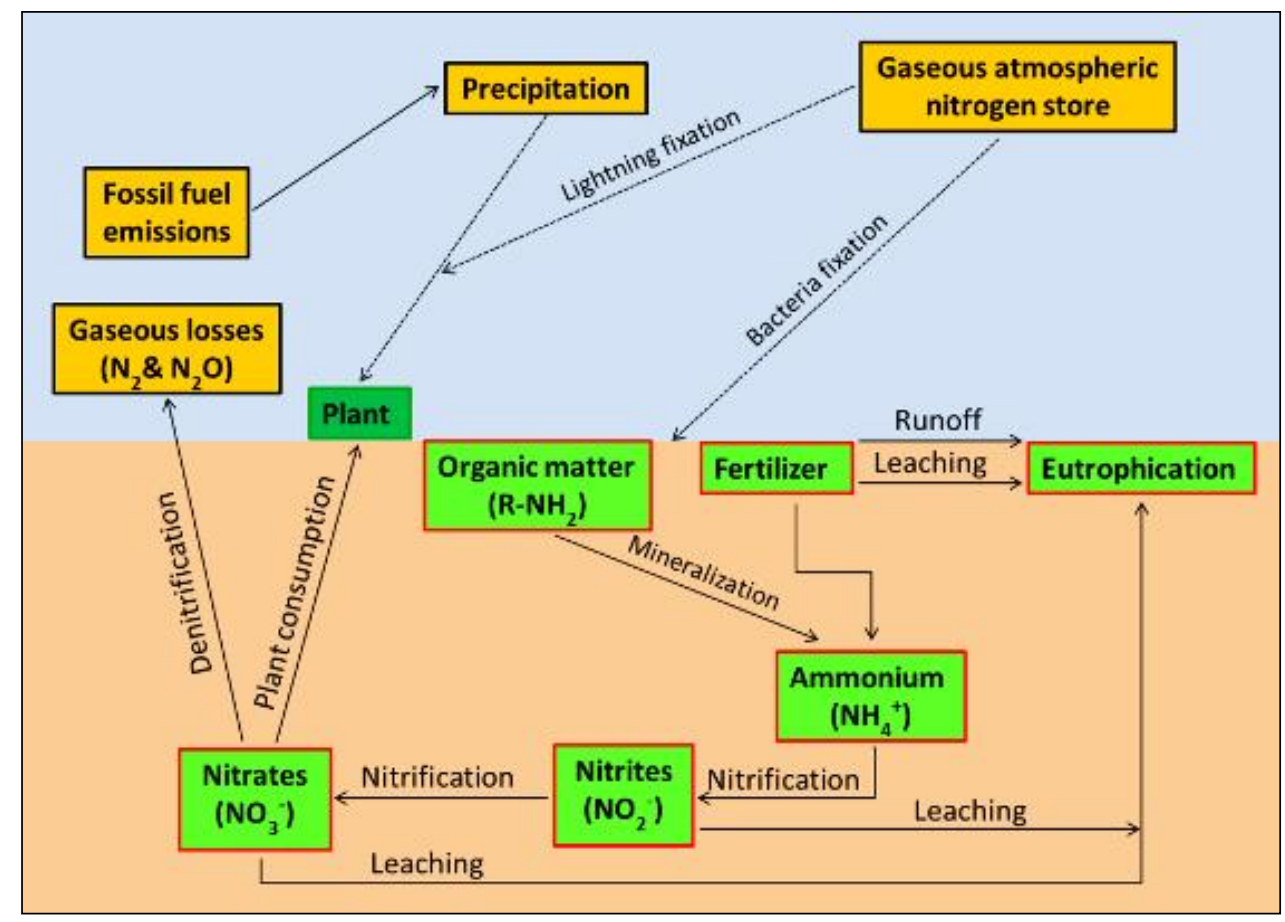

Fig. 2. Nitrogen cycle: Modes of formation and escape

\section{Urea Pollution Remediation}

Researchers are investigating different methods and mechanisms to minimize losses during fertilization for high crop yield. The urea performance may be improved by urease inhabitation of nitrogen, nitrification inhabitation of nitrogen, and slow-release of nitrogen from the fertilizer (Zarei and Ghaffarian 2013; Naz and Sulaiman 2016b). The use of controlled-release urea for slowing down nitrogen leaching has recently been practiced by farmers worldwide. Controlled-release fertilizers are generally produced by coating the granular fertilizer and producing a physical barrier at the surface to control the water penetration into the core. This released nitrogen from the core would slow down and the farmers can achieve good performance of the fertilizer. One determined advantage of this fertilizer allows nutrients in the soil to be available for longer periods of time (Suherman and Anggoro 2011). The density, physical properties, and compactness of the coated layer also need to be deliberated for an effective coating process (Du et al. 2006; Naz and Sulaiman 2016a).

The release rate of coated urea specifically depends on the coating thickness, surface micropores, and hydrolytic and microbial degradation of the coating. Coatings are classified into perfect coatings, cracked coatings, and damaged coatings repaired with wax. Both the chemical nature and physical properties of a coating influence the release rate of the coated fertilizers. For the production of slow-release fertilizers, various synthetic and natural materials, including neem, sulfur, resins, and synthetic polymers, have been used (Saleh and Hemanti 2003). It has been reported that neem and sulfur coatings do not meet the slow-release standards. Furthermore, these materials are costly and produce inconsistent coatings. 
The most effective materials for slow-release coatings are synthetic polymers. However, such coatings are relatively expensive, non-biodegradable, and not ecofriendly (Saleh and Hemanti 2003). For an effective use of the coated fertilizers, there is a need for low-cost biodegradable coating materials, such as carbohydrate polymers, ammonium chloride, zinc sulphate, copper sulphate, potassium chloride, and phosphogypsum (Saleh and Hemanti 2003). Being low cost and abundantly available, starches can also be used as biodegradable polymers for producing coated fertilizers (Naz et al. 2015).

The use of starch has extended from a common food ingredient to many industrial and technological applications over the last few decades. For example, starch is used as biodegradable material in pharmaceutical and agro-based industries. Due to its complex rheological traits, modified starch polymers have been investigated by many researchers (Liu et al. 2009; Lu et al. 2009; Naz and Sulaiman 2016b). Native starch is regenerated from water and $\mathrm{CO}_{2}$ in the plant through photosynthesis. The cellulose consists of linear chain of D-glucose units joined in $\beta(1,4)$ linkages whereas starch consists of glucose monomers joined in $\alpha(1,4)$ linkages.

The native starches are modified with water and other chemicals to obtain liquid polymers for different applications (Kamoun 2016; Naz and Sulaiman 2016b). Chemical modification is often required to induce flexibility and specific physical and rheological traits in starch gel.

After treatment with urea and disodium tetraborate, the physical and chemical properties of the native starch can be tailored to meet the coating requirements (Levine et al. 1959; Tudorachi et al. 2000; Ding et al. 2013). These additives are capable of converting the simple structures of starch into long-chained networks of complex rheological responses (Jin et al. 2012; Czech et al. 2013). Urea works as a plasticizer in this formulation and enables the movement of polymer chains. The borate ions, which dissociate from disodium tetraborate, facilitate the cross-linking of the molecules. The free sodium ions during the dissociation of disodium tetraborate are believed to shield the charges on the polymer chains (Jin et al. 2012).

Because the degree of cross-linking governs the gelatinization rate, a small quantity of these additives may greatly alter the rheological traits of the starch dispersion. The crosslinking also reduces the cracking of the starch granules at high temperature and stirring rates. The chemical modification process is performed to give an anionic or cationic character to the starches.

Through chemical modification, starches receive additional properties enabling their applications in agriculture and food processing industries and various technical sectors. Modified starches represent an estimated worldwide volume of 6.8 million tons and are still a rapidly growing segment of the global starch market (Xiaofei et al. 2004; Glibert et al. 2006).

In the present work, corn starch was processed in a water medium with urea and borate. A set of samples of pure and modified corn starch was prepared, and the rheological response was tested. The synthesized samples were also tested for their physical barrier to nitrogen release by coating over the granular urea and performing the basic nitrogen release experiments. 


\section{EXPERIMENTAL}

\section{Materials}

Modification of corn starch

The food grade corn starch was purchased from the local market of Faisalabad, Punjab, Pakistan. The starch was dried in daylight for $6 \mathrm{~h}$. The de-ionized water was the major constituent of the coating formulation, whereas urea and borate were also added in fractional amounts. Both the chemicals were of analytical reagent grade. These chemicals were imported from Sigma-Aldrich, Darmstadt, Germany. The as-synthesized starch-based coating samples were analyzed for their rheological and coating responses. Table 1 shows the chemical composition of the modified corn starch.

Starch is the major source of the nutritive energy for human being and plays significant role in meeting worldwide food demand. This research deals with the use of starch for coating, which has already finished its shelf life and remains unfit for food products. Since thousands of tonnes of expired starch is dumped every year, the focus should be on the use of bad, rotten, or spoiled starches in promoting the controlled release fertilizers' industry. This particle would help ensuring the food security and preventing the deterioration of environment.

Table 1. Chemical Composition of the Modified Corn Starch

\begin{tabular}{|c|c|c|c|c|}
\hline Sample & $\begin{array}{c}\text { Deionized } \\
\text { Water } \mathbf{( m L})\end{array}$ & Corn Starch (g) & Urea (g) & Borate (g) \\
\hline S-1 & 1000 & 50 & - & - \\
\hline S-2 & 1000 & 50 & 20 & - \\
\hline S-3 & 1000 & 50 & - & 20 \\
\hline S-4 & 1000 & 50 & 20 & 20 \\
\hline
\end{tabular}

The sample S-1 was prepared in a stainless-steel container with $1000 \mathrm{~mL}$ of deionized water. The water was heated to $85{ }^{\circ} \mathrm{C}$, and the solution was continuously stirred with an overhead stirrer for uniform mixing and efficient heat transfer. After attaining the desired temperature, $50 \mathrm{~g}$ of corn starch was mixed in hot water and reacted for $30 \mathrm{~min}$ at constant temperature. The native starch (S-1) sample was left to cool at room temperature. After $24 \mathrm{~h}$ of cooling, the stabilized sample was characterized and coated over granular urea. For preparation of sample $\mathrm{S}-2,50 \mathrm{~g}$ of corn starch was prepared similarly to sample $\mathrm{S}-1$. The heating of the starch dispersion was reacted for $10 \mathrm{~min}$. Thereafter, $20 \mathrm{~g}$ of urea was added to the dispersion. A further heating of the solution was conducted for complete gelation. The process was repeated with the addition of $20 \mathrm{~g}$ of each urea and borate to produce samples S-3 and S-4. To evaluate the influence of chemical additives on the rheological response of the samples, the gelatinization time, surface tension viscosity, density, loss modulus, and storage modulus of the samples were measured using different characterization techniques.

\section{Methods}

\section{Urea coating experiments}

Once the rheological response of the coating solutions was fully characterized, each was coated over granular urea using an in-house built swirling fluidized bed spray coater. The purpose of this test was to check the suitability of the developed materials for 
producing slow-release-coated fertilizers. The solution atomizer was mounted just above the air distributor of the coating reactor. The distance between the atomizer and the swirling bed was varied from 10 to $160 \mathrm{~mm}$ to produce uniformly coated urea. Such arrangements help minimize the pre-coat drying of the coating solution and improve the coating uniformity and efficiency of the coated urea. Through pneumatic mass flow, sufficient kinetic energy was provided from the bottom of the bed to keep the wet particles in the stable state of fluidization during the coating process. Uniformly coated urea batches were produced under optimized bed spray coating conditions.

The granular urea was supplied by the Fatima Group, Sheikhupura, Punjab, Pakistan under the brand name Sarsabz Urea. A batch of $300 \mathrm{~g}$ urea (with an average particle size of $3.45 \mathrm{~mm}$ ) was fluidized above its minimum level of fluidization. An air blower (TongYang Plant, Seoul, South Korea) was used to supply bottom-up air for fluidization of the urea batch. The coating solutions were atomized and sprayed over the fluidizing urea. The solution was pneumatically delivered to the urea. The solution was delivered for $300 \mathrm{~ms}$ after every $10 \mathrm{~s}$. Each urea batch was exposed to five spray injections. Once the coating process was over, the coated urea was dried at $60{ }^{\circ} \mathrm{C}$ to remove all moisture. The fully dried urea samples were stored in moisture-free containers.

Both the uncoated and coated urea samples were inspected for coating thickness, percentage of coating material, coating morphology, nutrient discharge rate, complete dissolution time, and coating strength. Scanning electron microscopy (SEM) (Hitachi, Tokyo, Japan) techniques were used to elaborate on the surface morphology and coating thickness of the urea samples. The average of all of the size differences between the coated and uncoated urea particles allowed for the calculation of the average coating thickness. The crushing strength of the coated and uncoated urea was measured with a TBH-325-TD tablet tester (Erweka, Heusenstamm, Germany). The TBH-325-TD tester measures the crushing strength of a sample in terms of constant force $(\mathrm{N})$. The force required to crack the coating is called coating sensitivity. This instrument can measure the coating sensitivity in the range of 3 to $40 \mathrm{~N}$. A dissolution rate test was conducted to measure the discharge time of the uncoated and coated urea. In this test, the urea was released in distilled water under a shear rate of $200 \mathrm{rpm}$. Both the coated and uncoated urea samples were weighed to $5 \mathrm{~g}$ and placed in separate glass beakers. A total of $100 \mathrm{~mL}$ of distilled water was added to each sample, and the urea-water mixture was stirred at room temperature by using an overhead stirrer. The time for complete release of urea into distilled water was noted.

\section{RESULTS AND DISCUSSION}

\section{Physical Properties of Coating Gel}

For most applications, starch is suspended in water above its gelatinization temperature (Overbeek 2010). The gel viscosity is influenced by numerous parameters including the type of the starch, concentration of solid, $\mathrm{pH}$ of suspension, heating rate, stirring rate, reaction time, temperature, and impurities (Deka and Dey 2013). The reaction conditions applied to a particular suspension of the starch may likewise change the gelatinization temperature (Yin et al. 2013; Naz and Sulaiman 2015). The practical uses of starches include their suspension in water at temperatures marginally over the gelatinization temperature (Overbeek 2010). The imposed processing conditions may notably change the time and temperature of gelatinization of the starch suspension (Yin $e t$ al. 2013). The possible changes in the viscosities of the modified and native starches is 
reported in Fig. 3. After 15 min of heating, the S-1 sample achieved maximum viscosity at a constant heating temperature of $85^{\circ} \mathrm{C}$. The viscosity of the native starch suspension was reduced 36 points when the suspension was further heated after $15 \mathrm{~min}$. After $25 \mathrm{~min}$, the suspension viscosity remained constant and remained unchanged over time. The S-1 peak viscosity was measured at approximately $299 \mathrm{cP}$. Similar viscosity plots were obtained for samples S-2, S-3, and S-4. However, the peak viscosities of all three samples were found higher than the native starch. The viscosity curves of these samples attained the peak values slightly later than the peak value of the native starch. Likewise, the lessening of viscosity of the modified starch after attaining the peak value had not been as noticeable as that of pure starch.

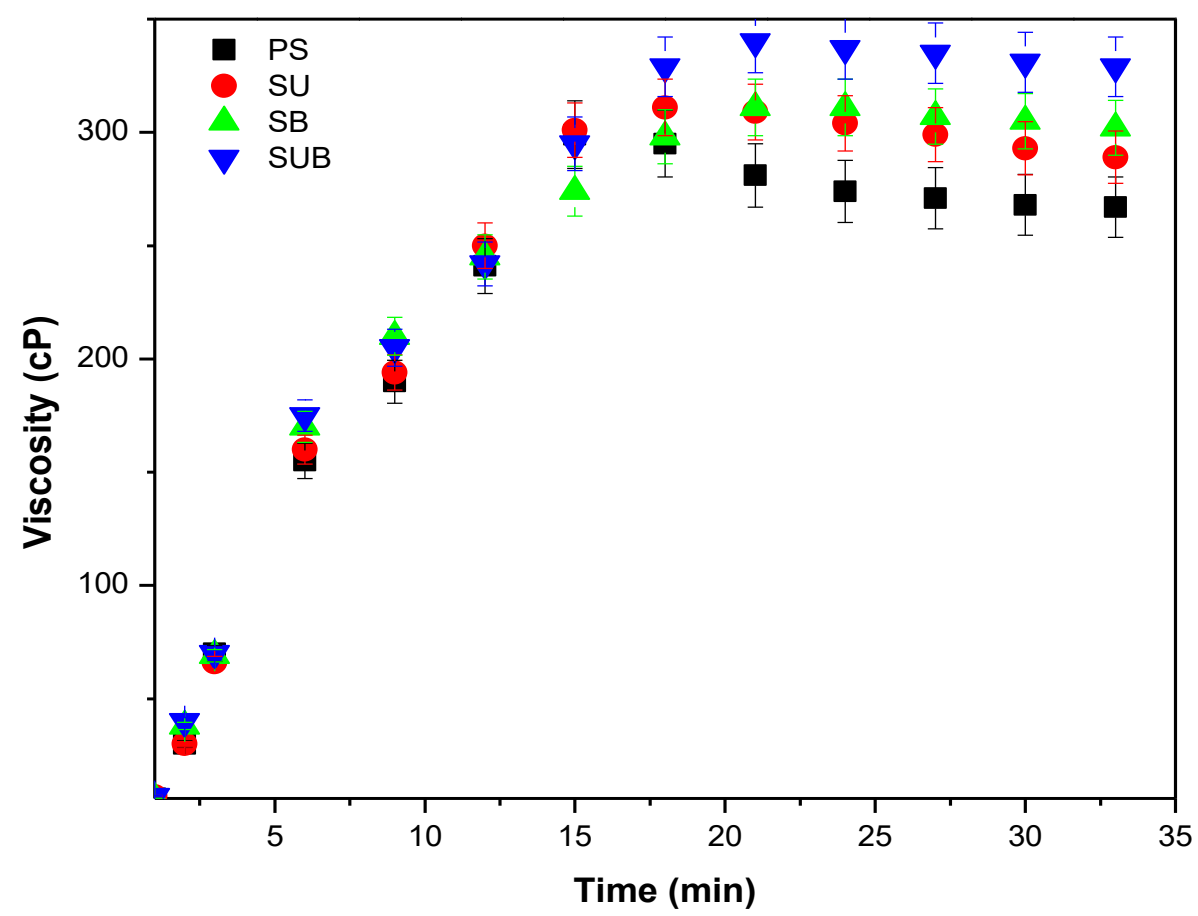

Fig. 3. The time dependent viscosity of pure and chemically modified starch

The alleviation of viscosity with time from the peak value might be ascribed to high process temperature and prolonged heating of the suspension. Because the temperature of decomposition of the starch granules is reported as lower than its melting point (Liu et al. 2009), the granules rapidly expand and crack over time. Figure 4 depicts the swelling of the starch granules in the heated suspension. Upon cracking, the suspension loses its tightness, and consequently the viscosity becomes lower.

The deformation and cracking of the starch particles over time is illustrated in Fig. 5. The viscosity profile reflected the possible variations in the granule's shape during the processing of the starch. Figure 5 presents the thermally processed corn starch. The viscosity profile exhibited a linearly increasing trend at early stages of starch processing due to swelling of the granules and amylose leaching. After 7 min of heating, the starch granules completely swelled out and the viscosity profile reached the peak point. Beyond this point, heat treatment of the suspension resulted in a viscosity breakdown due to the shear field of the instrument and consequently a decrease in viscosity. 


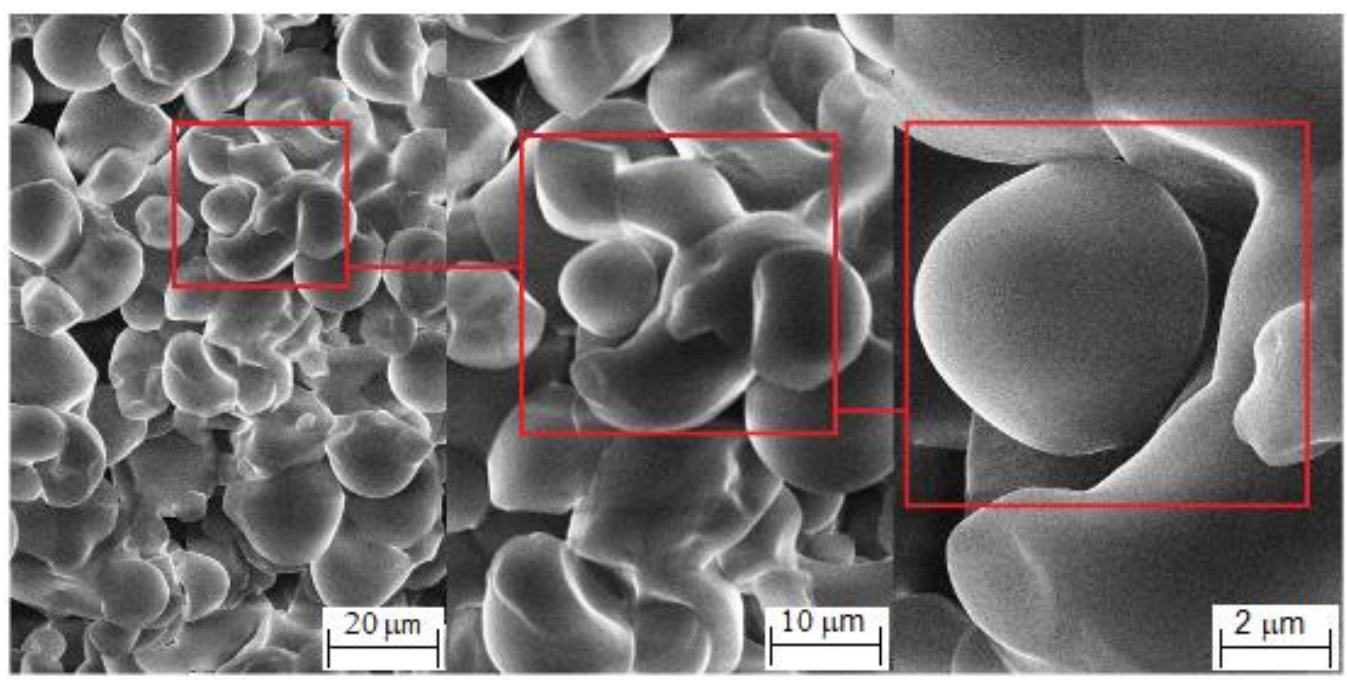

Fig. 4. Pre-cracking SEM micrographs of swelled starch particles

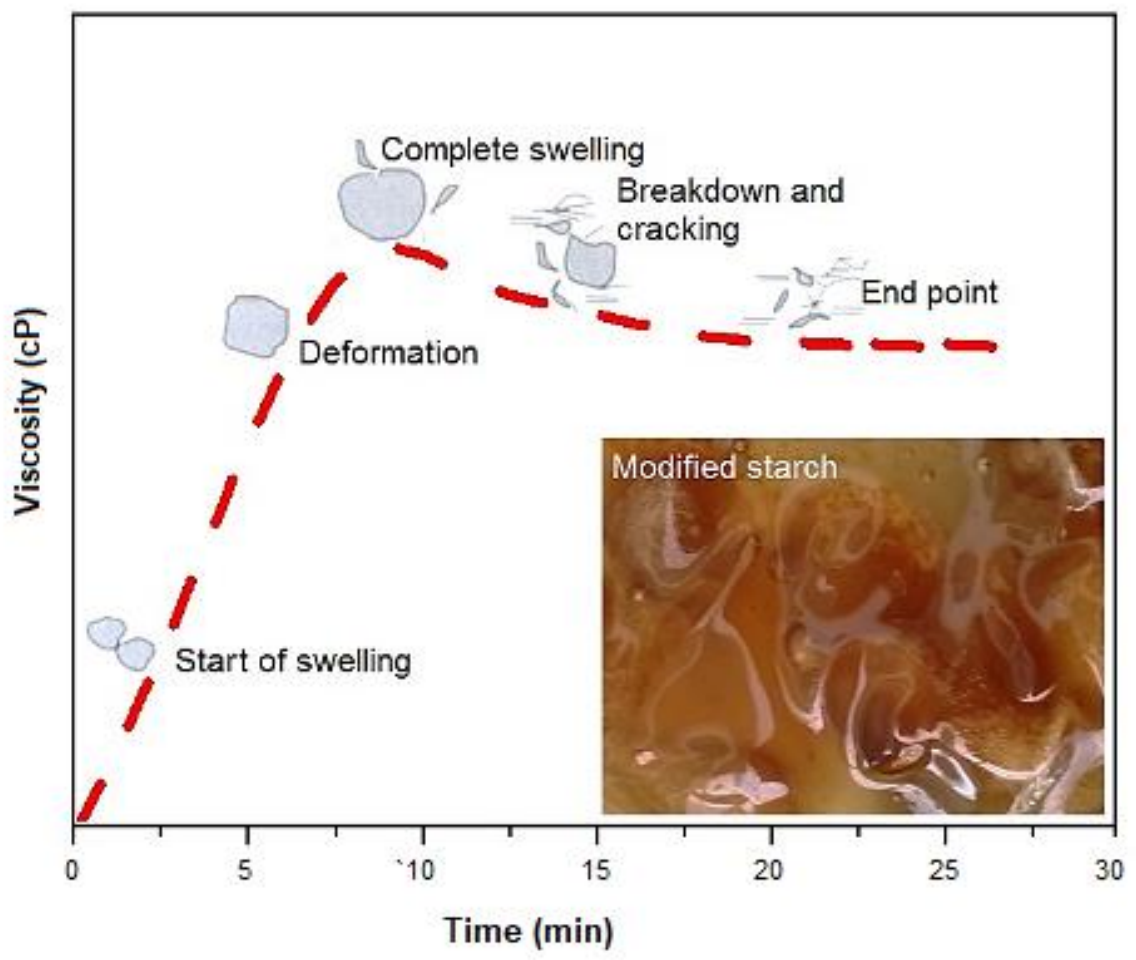

Fig. 5. Illustration of time-based starch swelling on viscosity profile of S-4 sample

The suggested viscosity breakdown in Fig. 5 can be avoided by introducing crosslinking and plasticizing agents in the suspension (Ali and Hasnain 2013; Ariyanti et al. 2013). Figure 3 suggests that the presence of borate and urea in the formulation caused a small change between the peak viscosity and the final viscosity of the chemically altered starch. These modifiers notably improved the stability of the suspension by reducing the starch cracking. In response, the suspension retained its tightness and the viscosity breakdown was not as detrimental as it was for pure starch (S-1). The S-4 sample gained the highest viscosity among the investigated samples. The high viscosity was attributed to di-sodium tetraborate in the dispersion, which dissociated into borate and sodium ions. The 
reactive borate ions formulated the polymer chains through hydrogen bonding with the starch, whereas the charge on the developed chains was shielded by the free $\mathrm{Na}^{+}$ions (Jin et al. 2012). The formation of a borate-polyols complex due to hydrogen bonding contributes to viscosity enhancement of the sample (Naz et al. 2014).

A comparison of the storage modulus of samples S-1 and S-4 is provided in Fig. 6 . The storage modulus is referred to the elastic response of the starch gel. The time-based storage modulus plots revealed good stability of the S-4 sample over the S-1 sample. The pure starch began to destabilize after $300 \mathrm{~s}$ of test time, which suggests low stability over time. The sharply decreasing storage modulus of the native starch suspension reflects an unstable gel structure (S-1 sample). The gel of native starch started to quickly break down over the test time. In contrast, the modified samples retained their gel structures over longer periods of time. The inset provides a comparison of native and chemically modified starch frequency sweep response at $1 \%$ strain. These frequency sweep profiles provide information about the storage and loss moduli with a change in angular frequency. The storage modulus of the modified starch was reported as higher than the loss modulus, which confirms the gel formation character of the modified starch and dense fluid-like character of the pure starch. It was worth noting that the magnitude of $G^{\prime}$ and $G$ ' ' for strong gel should reach up to one million. Because the magnitude of $G$ ' and $G$ ' ' of the modified starch were not as high as required for a strong gel, it was regarded as a weak gel. The unmodified starch sample was fluid in nature where the $G$ ' component dominated the $G$ ' at lower angular frequencies. However, at higher frequencies, both components showed close agreement (Jin et al. 2010; Naz et al. 2014).

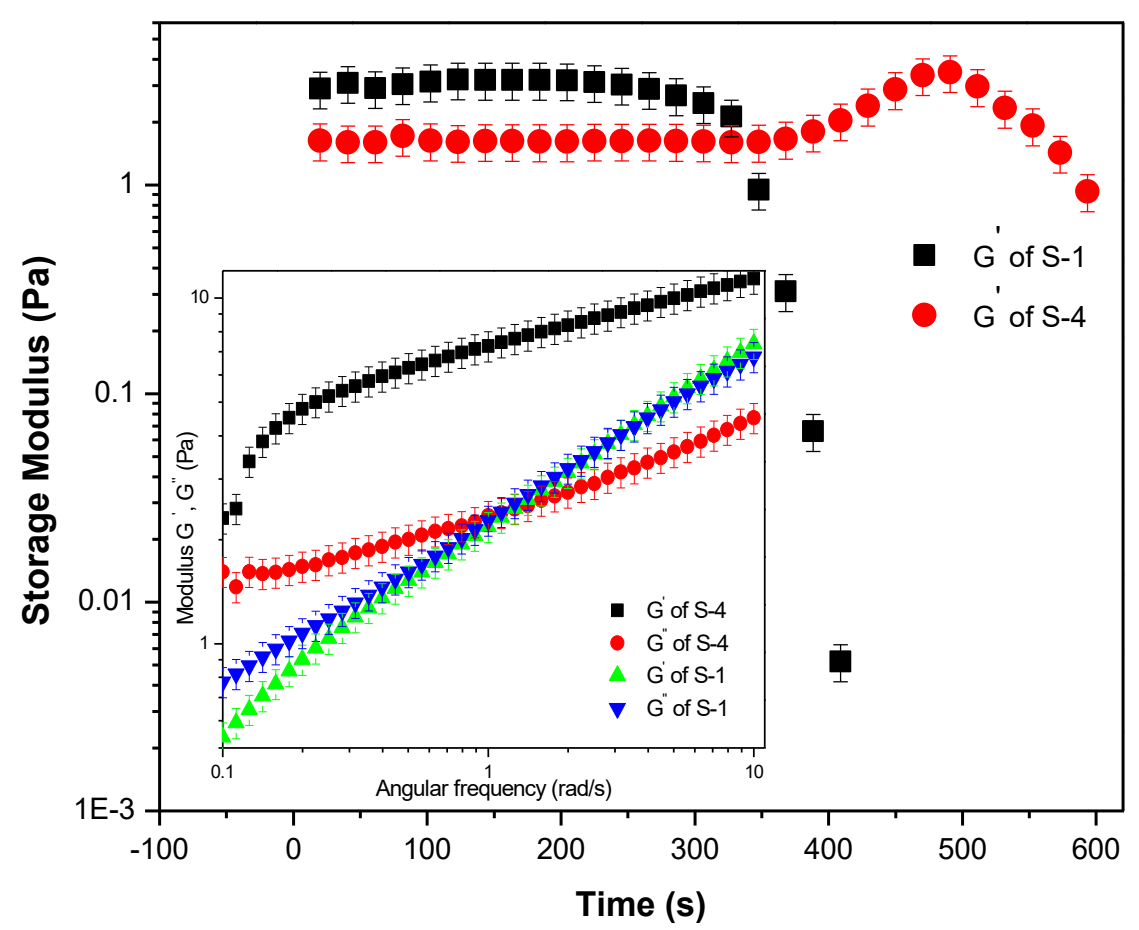

Fig. 6. The time-dependent storage moduli of native and chemically altered starches

\section{Coating Properties}

The response of elastic and viscous components suggests that during spray coating applications it would be difficult to break the modified starch into fine spray droplets at 
low injection pressures. Therefore, the gel would break into larger droplets, which may result in non-uniform and thick coatings and consequently waste the material. To achieve a fine spray size, the gel was pre-spray heated at $80{ }^{\circ} \mathrm{C}$ to ease the flow and breakup process. The granular urea was coated with a fine spray of pure and modified starch samples and tested for its surface morphology and slow-release parameters. The surface morphology was elaborated from the SEM micrographs of the coated and uncoated granules. Some of the micrographs are shown in Fig. 7. The SEM study revealed a less dense surface morphology of the uncoated urea with a high degree of roughness. The porosity of the uncoated granules was also found quite high as compared to the coated granules. The surface of the coated granules was found uniform, dense, and hard with low porosity.

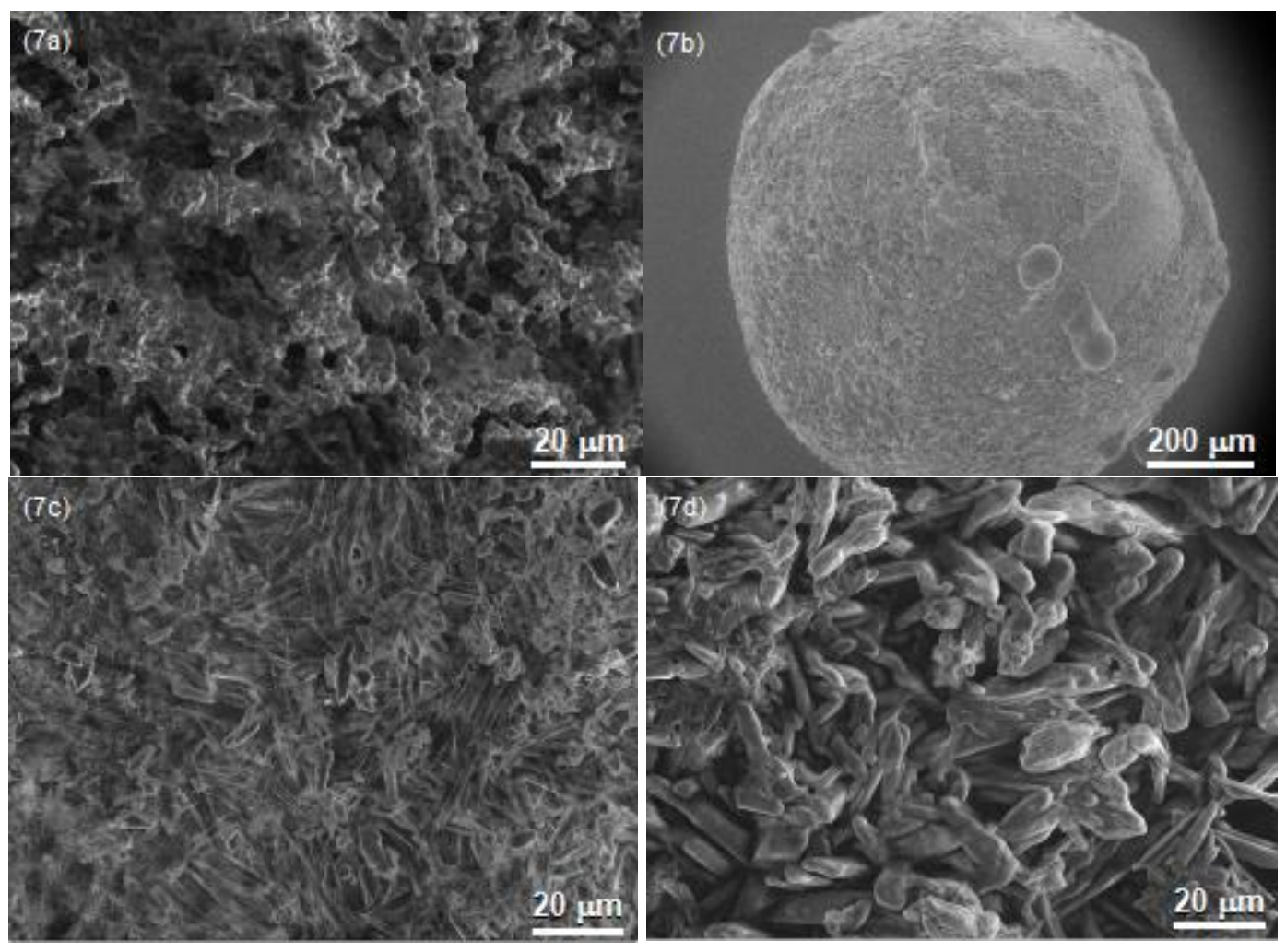

Fig. 7. SEM micrographs of uncoated and coated urea granules: (7a) uncoated urea, (7b) Coated with sample S-4, (7c) Coated with sample S-4, and (7d) Coated with sample S-4

Both the coated and uncoated granules were also analyzed for their average diameter, coating thickness, dissolution rate, and coating strength. The thickness of the coating was measured by measuring the difference between the diameters of the uncoated and coated granules. For thickness measurement, 10 coated and uncoated granules were randomly selected and their diameters were carefully measured. The difference of the diameters of all 10 measurements was averaged to obtain the mean coating thickness, as shown in Fig. 8. The smallest diameter of the coated granules was found for coating S-1 followed by S-2, S-3, and S-4. This change in diameter with coating type was attributed to the coating viscosity. With the highest viscosity, the S-4 sample produced the thickest coating among all of the tested samples. Overall, the average coating thickness remained in the range of $0.6 \mathrm{~mm}$ to $1.05 \mathrm{~mm}$. 


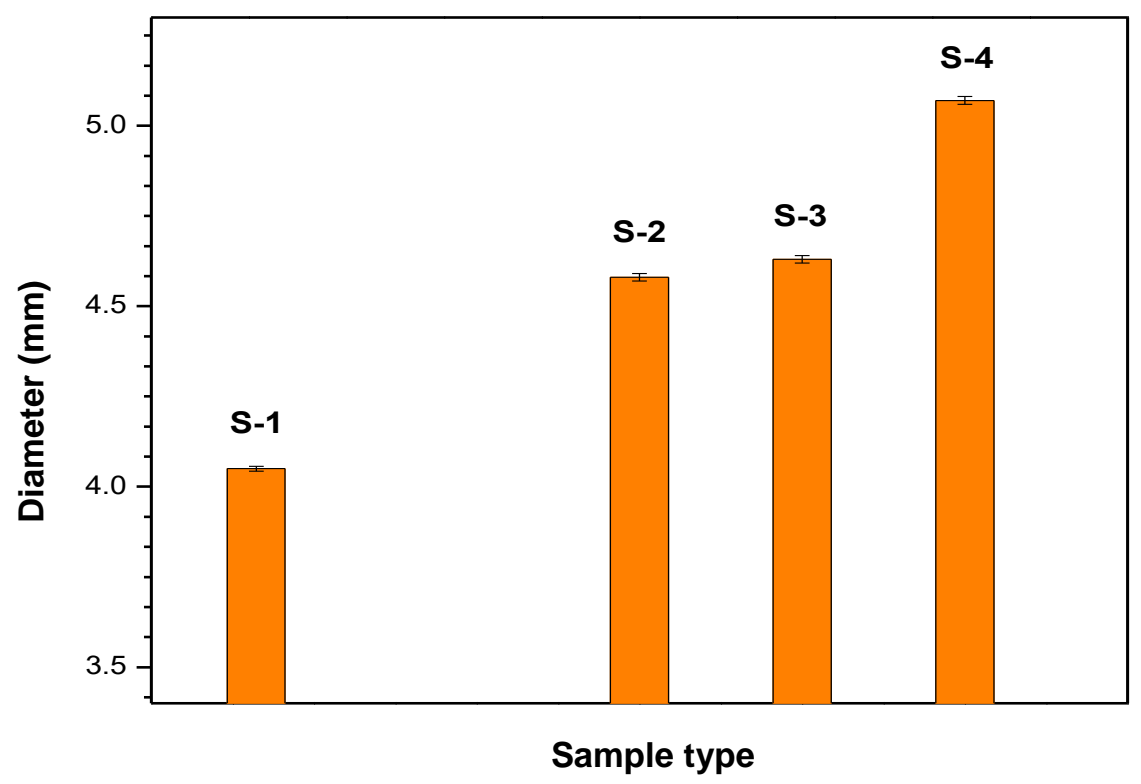

Fig. 8. Average diameter of the coated granules

The efficiency of the physical barrier of the coating to the water diffusion and nutrients' leaching was examined through a dissolution test. A total of $10 \mathrm{~g}$ of both coated and uncoated samples was taken in separate beakers containing $100 \mathrm{~mL}$ of water. The beakers were gently shaken with a mechanical shaker, and the time of complete release of the coated and uncoated granules was recorded. The release time of the uncoated urea was approximately $6 \mathrm{~min}$. Figure 9 reports the release time of the urea samples coated with $\mathrm{S}$ $1, \mathrm{~S}-2, \mathrm{~S}-3$, and S-4 formulations. A usual, quick release of the uncoated urea was predicted when compared to the coated samples. The uncoated urea was completely released into water after $6 \mathrm{~min}$. Alternatively, the slowest release rate was predicted from the urea coated with the S-4 formulation followed by S-3, S-2, and S-1. It took almost $32 \mathrm{~min}$ for complete release of urea from the $\mathrm{S}-4$ coating.

The surface porosity also influenced the release of a coated urea. The SEM micrographs in Fig. 7 revealed high surface porosity of the uncoated urea as compared to the coated one. Unlike the unprocessed urea, the surface of the coated urea was denser and less spongy. The results were in line with the findings of Vashishtha et al. (2010). The borate in the coating formulation developed as a physical barrier to the water diffusion into the core and conversely the nutrients leaching into the water. The percent release of the coated urea was analyzed by considering the zero- and first-order kinetic models. Zeroorder kinetics is a process in which the release rate does not depend on nitrogen concentration. In first-order kinetics, the release rate depends on the concentration of the nitrogen. A higher nitrogen concentration results in a faster release rate. The urea release followed the zero-order kinetic model (Cahill et al. 2010). The release plots of urea coated with S-2, S-3, and S-4 formulations were segmented into three distinguishable regions: lag region, linear region, and complete decay region. The lag region was found between 0 to 5 min, the linear region was designated as 5 to $11 \mathrm{~min}$, and thereafter a steady stage was reached. 


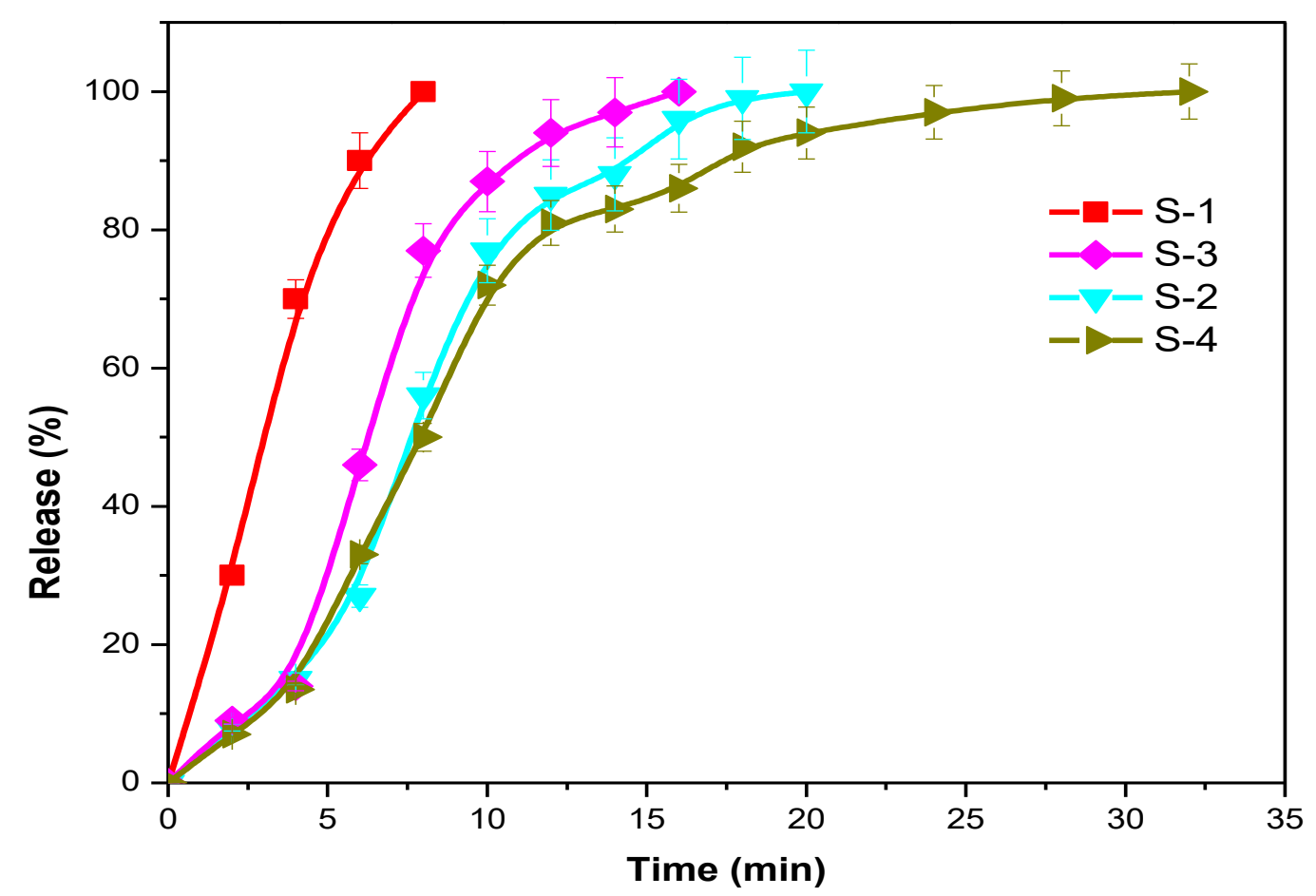

Fig. 9. Release rate of the coated urea samples

The crushing strength of the coated and uncoated urea was also investigated in this work. Crushing strength is the measure of the minimum force required to crush a granule. Ten granules were randomly selected from each sample and crushed with the tablet tester. The corresponding crushing strengths were averaged to obtain the mean value. The S-4 coated granules exhibited the highest crushing strength of $30.5 \mathrm{~N}$, which was considerably higher than the crushing strength of the uncoated urea $(22.2 \mathrm{~N})$. However, the crushing strength of the coated urea decreased slightly over time. The coated urea was packed in plastic bags and stored for 2 months at room temperature. After 2 months, the crushing strength was measured again and compared with pre-storage measurements. The pre-and post-storage measurements showed almost a $2.8 \%$ reduction in the crushing strength. Longer storage times may adversely influence the crushing strength, especially in humid conditions. An increase in moisture content in the coated layer with time softens the physical barrier of the coating and consequently the crushing strength ( $\mathrm{Lu}$ et al. 2012).

\section{CONCLUSIONS}

1. The starches, modified with urea and borate, showed good stability and mechanical strength over time. A decrease in the storage modulus of the native starch showed unstable gel structure, which may break after some time. The modified starch was regarded as a weak gel, and its storage modulus dominated the loss modulus. However, the viscous component dominated the elastic component at lower angular frequencies for the native starch.

2. A small difference between the peak and end point viscosities of the modified starch suggested that the presence of urea and borate in the starch suspension considerably 
reduced the starch cracking. In response, the starch granules in the suspensions retained their tightness, and the breakdown was not as extensive as that of a pure starch sample (S-1). The S-4 sample gained the highest viscosity among the investigated samples.

3. During study of the coating urea, SEM analyses showed a less dense surface morphology of the uncoated urea with a high degree of roughness. The porosity of the uncoated granules was also quite high compared to the coated granules. The surface of the coated granules was uniform, dense, and hard with low porosity.

4. Fast release of the uncoated urea was predicted compared to the coated samples. The uncoated urea was completely released into water after $6 \mathrm{~min}$. Conversely, the slowest release was predicted from the urea coated with the $S-4$ formulation followed by $S-3$, $\mathrm{S}-2$, and S-1. It took approximately $32 \mathrm{~min}$ for the complete release of urea coated with the $\mathrm{S}-4$ formulation.

5. The S-4 coated granules exhibited the highest crushing strength of $30.5 \mathrm{~N}$, which was noticeably higher than the crushing strength of the uncoated urea $(24.2 \mathrm{~N})$. Howver, the crushing strength of the coated urea decreased slightly over time.

\section{ACKNOWLEDGEMENTS}

This work was sponsored by King Saud University, Riyadh under the Research Group Project No. RG-1438-020.

\section{REFERENCES CITED}

Ali, T. M., and Hasnain, A. (2013). "Morphological, physicochemical, and pasting properties of modified white sorghum (sorghum bicolor) starch," International Journal of Food Properties 17(3), 523-535. DOI: 10.1080/10942912.2012.654558

Ariyanti, S., Man, Z., and Azmi, B. M. (2013). "Improvement of hydrophobicity of urea modified tapioca starch film with lignin for slow release fertilizer," Advanced Materials Research 626, 350-354. DOI: 10.4028/www.scientific.net/AMR.626.350

Boyer, E. W., Goodale, C. L., Jaworski, N. A., and Howarth, R. W. (2002). "Anthropogenic nitrogen sources and relationships to riverine nitrogen export in the Northeastern USA," Biogeochemistry 57(1), 137-169. DOI: 10.1023/A:1015709302073

Cahill, S., Osmond, D., and Israel, D. (2010). "Nitrogen release from coated urea fertilizers in different soils," Communications in Soil Science and Plant Analysis 41(10), 1245-1256. DOI: 10.1080/00103621003721437

Czech, Z., Wilpiszewska, K., Tyliszczak, B., Jiang, X., Bai, Y., and Shao, L. (2013). "Biodegradable self-adhesive tapes with starch carrier," International Journal of Adhesion and Adhesives 44, 195-199. DOI: 10.1016/j.ijadhadh.2013.03.002

Deka, A., and Dey, N. (2013). "Rheological studies of two component high build epoxy and polyurethane based high performance coatings," Journal of Coatings Technology and Research 10(3), 305-315. DOI: 10.1007/s11998-012-9445-3 
Ding, R., Su, C., Yang, Y., Li, C., and Liu, J. (2013). "Effect of wheat flour on the viscosity of urea-formaldehyde adhesive," International Journal of Adhesion and Adhesives 41, 1-5. DOI: 10.1016/j.ijadhadh.2012.08.003

Du, C. W., Zhou, J. M., and Shaviv, A. (2006). "Release characteristics of nutrients from polymer-coated compound controlled release fertilizers," Journal of Polymers and the Environment 14(3), 223-230. DOI: 10.1007/s10924-006-0025-4

Galloway, J. N., and Cowling, E. B. (2002). "Reactive nitrogen and the world: 200 years of change," Ambio: A Journal of the Human Environment 31(2), 64-71. DOI: 10.1579/0044-7447-31.2.64

Galloway, J. N., Townsend, A. R., Erisman, J. W., Bekunda, M., Cai, Z., Freney, J. R., Martinelli, L. A., Seitzinger, S . P., and Sutton, M. A. (2008). "Transformation of the nitrogen cycle: Recent trends, questions, and potential solutions," Science 320(5878), 889-893. DOI: $10.1126 /$ science. 1136674

Glibert, P., Harrison, J., Heil, C., and Seitzinger, S. (2006). "Escalating worldwide use of urea - A global change contributing to coastal eutrophication," Biogeochemistry 77(3), 441-463. DOI: 10.1007/s10533-005-3070-5

Jin, S., Wang, Y., He, J., Yang, Y., Yu, X., and Yue, G. (2012). "Preparation and properties of a degradable interpenetrating polymer networks based on starch with water retention, amelioration of soil, and slow release of nitrogen and phosphorus fertilizer," Journal of Applied Polymer Science 128(1), 407-415. DOI: 10.1002/app.38162

Jin, Y., Cheng, X., and Zheng, Z. (2010). "Preparation and characterization of phenolformaldehyde adhesives modified with enzymatic hydrolysis lignin," Bioresource Technolology 101(6), 2046-2048. DOI: 10.1016/j.biortech.2009.08.111

Kamoun, E. A. (2016). "N-succinyl chitosan-dialdehyde starch hybrid hydrogels for biomedical applications," Journal of Advanced Research 7(1), 69-77. DOI: 0.1016/j.jare.2015.02.002

Levine, S. Griffin, H. L., and Senti, F. R. (1959). "Solution properites of dialdehyde starch," Journal of Polymer Science, 35(128), 31-42. DOI: 10.1002/pol.1959.1203512804

Liu, H., Xie, F., Yu, L., Chen, L., and Li, L. (2009). "Thermal processing of starch-based polymers," Progress in Polymer Science 34(12), 1348-1368. DOI:

10.1016/j.progpolymsci.2009.07.001

Lu, D. R., Xiao, C. M., and Xu, S. J. (2009). "Starch-based completely biodegradable polymer materials," eXPRESS Polymer Letters 3(6), 366-375. DOI: 10.3144/expresspolymlett.2009.46

Lu, P., Zhang, M., Li, C., and Liu, Z. (2012). "Effect of acid-modified clay on the microstructure and performance of starch films," Polymer-Plastics Technology and Engineering 51(13), 1340-1345. DOI: 10.1080/03602559.2012.702252

Naz, M. Y., and Sulaiman, S. A. (2015). "Physico-chemical properties of carbohydrate polymer coatings for slow release urea industry," Main Group Chemistry 14(1), 3542. DOI: $10.3233 / \mathrm{MGC}-140151$

Naz, M. Y., and Sulaiman, S. A. (2016a). "Attributes of natural and synthetic materials pertaining to slow-release urea coating industry," Reviews in Chemical Engineering 33(3), 293-308. DOI: 10.1515/revce-2015-0065

Naz, M. Y., and Sulaiman, S. A. (2016b). "Slow release coating remedy for nitrogen loss from conventional urea: A review," Journal of Controlled Release 225, 109-120. DOI: $10.1016 /$ j.jconrel.2016.01.037 
Naz, M. Y., Sulaiman, S. A., Ariwahjoedi, B., and Shaari, K. Z. K. (2014). "Characterization of modified tapioca starch solutions and their sprays for high temperature coating applications," The Scientific World Journal 2014, Article ID 375206. DOI: 10.1155/2014/375206

Naz, M. Y., Sulaiman, S. A., and Man, Z. (2015). "Time function DualPDA study of spray growth and droplet size-velocity profiles of chemically modified tapioca starch," Aerosol and Air Quality Research 15(5), 1699-1711. DOI: 10.4209/aaqr.2015.02.0122

Overbeek, A. (2010). "Polymer heterogeneity in waterborne coatings," Journal of Coatings Technology and Research 7(1), 1-21. DOI: 10.1007/s11998-009-9201-5

Saleh, D. S., and Hemati, M. (2003). "Experimental study and modeling of fluidized bed coating and agglomeration," Powder Technology 130(1-3), 116-123. DOI: 10.1016/S0032-5910(02)00254-1

Suherman, I., and Anggoro, D. D. (2011). "Producing slow release rate urea by coating with starch/acrylic acid in fluid ced spraying," International Journal of Engineering \& Technology 11(6), 62-66.

Tudorachi, N., Cascaval, C. N., and Rusu, M., and Pruteanu, M. (2000). "Testing of polyvinyl alcohol and starch mixtures as biodegradable polymeric materials," Polymer Testing 19(7), 785-799. DOI: 10.1016/S0142-9418(99)00049-5

Vashishtha, M., Dongara, P., and Singh, D. (2010). "Improvement in properties of urea by phosphogypsum coating," International Journal of ChemTech Research 2(1), 3644.

Xiaofei, M., Jiugao, Y., and Jin, F. (2004). "Urea and formamide as a mixed plasticizer for thermoplastic starch," Polymer International 53(11), 1780-1785. DOI: $10.1002 /$ pi. 1580

Yin, W., Zeng, X., Li, H., Lin, X., Ren, B., and Tong, Z. (2013). "Steady rheological behaviors of UV-curable waterborne hyperbranched polyurethane acrylate dispersions," Journal of Coatings Technology and Research 10(1), 57-64. DOI: $10.1007 / \mathrm{s} 11998-012-9432-8$

Zarei, A., and Ghaffarian, V. (2013). "Preparation and characterization of biodegradable cellulose acetate-starch membrane," Polymer-Plastics Technology and Engineering 52(4), 387-392. DOI: 10.1080/03602559.2012.752831

Article submitted: April 26, 2019; Peer review completed: July 6, 2019; Revised version received: August 4, 2019; Accepted: August 6, 2019; Published: August 9, 2019.

DOI: $10.15376 /$ biores.14.4.7775-7789 